\title{
ABSTRACTS
}

\section{ELDER-BROTHER-LIKE AND YOUNGER-BROTHER-LIKE}

\author{
By Miki, Yasumasa and Kimura, Yukiko \\ Tokyo University
}

\section{Problem.}

Despite their similarities, it is known that there are some personality differences between members of a pair of identical twins.

According to the observations of Suwa and Okada, it seems that some of these differences may be reduced to the differences between elderbrother-like characteristics and younger-brotherlike characteristics. These differences may be dependent on (1) the japanese family system in which elder son and younger son are differently treated by parents and other members of the family and (2) the superior-inferior relationship or interdepending relationships due to differences in physical and mental capacities between two members who are essentially identical and are always compared by others.

As the first approach to these problems, the authors tried to make up a convenient questionnaire to evaluate elder-brother-like personality and younger-brother-llke personality.

Subjects and procedures

Based on Suwa and Okada's observations on fraternal personality differences, a questionnaire consisting of 45 items was composed. Each item described on behavior characteristic. The subjects was expected to answer whether this characteristic was more dominant in him or in his brother. If it was difficult to decide, the subject was allowed to check "not known."

This questionnaire was answered by 31 pairs of mal identical twins, 24 pairs of female identical twins, and 274 boys (76 from residentical quarters, 105 from commercial and industrial quarters of Tokyo and 93 from rural area) and 256 girls
(62, 96,98 respectively). The non-twin all had siblings of the same sex and the age difference being less than 3 years. All subjects were 12-14 years old.

Results

Paw scores are shown in Table 2. These are summed up in Table 3 for each item according to whether differences between responses "elder" and "younger" are statistically significant or not. In this table the sign means that the item got significantly larger number of "elder responses in the group, while (s) means that the "younger" responses were prevailing. The signs (A) and (B) means that though the differences were significant, the item also had "not known" responses larger than the critical number. The sign A, B, $a$, and $b$ indicate that there were some tendencies but not significant.

Following results are found from Table 3.

1. Fraternal personality differences between nontwin sib ings were greater than those between identical twins.

2. Fraternal personality differences were greater in brothers than in sisters.

3. Younger-brother-like characteristics are more definite than the elder-brother-like characteristics.

4. Fraternal personality differences are more marked in rural children than in the city children, and more in commercial quarters than in residential quarters.

5. Fraternal personality differences were detected by following items.

1: item 22 Likes to play outdoors......younger 2. " 17 More easily influenced by others 